BMJ Open

Diabetes

Research

\& Care

\title{
HbA1c during early pregnancy reflects beta-cell dysfunction in women developing GDM
}

\author{
Latife Bozkurt, ${ }^{1}$ Christian S Göbl, ${ }^{2}$ Karoline Leitner, ${ }^{1}$ Giovanni Pacini, ${ }^{3}$ \\ Alexandra Kautzky-Willer (1) ${ }^{1}$
}

To cite: Bozkurt L, Göbl CS, Leitner K, et al. HbA1c during early pregnancy reflects beta-cell dysfunction in women developing GDM. BMJ Open Diab Res Care 2020;8:e001751. doi:10.1136/ bmjdrc-2020-001751

- Supplemental material is published online only. To view, please visit the journal online (http://dx.doi.org/10.1136/ bmjdrc-2020-001751).

Received 3 July 2020 Revised 23 September 2020 Accepted 1 October 2020

Check for updates

(c) Author(s) (or their employer(s)) 2020. Re-use permitted under CC BY-NC. No commercial re-use. See rights and permissions. Published by BMJ.

${ }^{1}$ Division of Endocrinology and Metabolism, Department of Internal Medicine III, Medical University of Vienna, Vienna, Austria

${ }^{2}$ Division of Obstetrics and Feto-maternal Medicine, Department of Obstetrics and Gynecology, Medical University of Vienna, Vienna, Austria ${ }^{3}$ Metabolic Unit, National Research Council Padua Research Area, Padova, Veneto, Italy

Correspondence to Dr Alexandra Kautzky-Willer; alexandra.kautzky-willer@ meduniwien.ac.at

\section{ABSTRACT}

Introduction It is of current interest to assess eligibility of hemoglobin A1C ( $\mathrm{HbA1C}$ ) as a screening tool for earlier identification of women with risk for more severe hyperglycemia in pregnancy but data regarding accuracy are controversial. We aimed to evaluate if $\mathrm{HbA} 1 \mathrm{C}$ mirrors pathophysiological precursors of glucose intolerance in early pregnancy that characterize women who develop gestational diabetes mellitus (GDM).

Research design and methods 220 pregnant women underwent an $\mathrm{HbA} 1 \mathrm{c}$ measurement as well as an oral glucose tolerance test (OGTT) with multiple measurements of glucose, insulin and C-peptide for evaluation of insulin sensitivity and beta-cell function at 16 th gestational week (IQR: 14-18). Clinical follow-ups were performed until end of pregnancy.

Results Increased maternal $\mathrm{HbA} 1 \mathrm{c} \geq 5.7 \%(39 \mathrm{mmol} /$ $\mathrm{mol}$ ) corresponding to pre-diabetes outside of pregnancy was associated with altered glucose dynamics during the OGTT. Pregnancies with early HbA1C $\geq 5.7 \%$ showed higher fasting ( $90.4 \pm 13.2$ vs $79.7 \pm 7.2 \mathrm{mg} / \mathrm{dL}, p<0.001)$, mean $(145.6 \pm 31.4$ vs $116.2 \pm 21.4 \mathrm{mg} / \mathrm{dL}, p<0.001)$ as well as maximum glucose concentrations and tended to a delay in reaching the maximum glucose level compared with those with normal-range $\mathrm{HbA1C}(186.5 \pm 42.6$ vs $147.8 \pm 30.1$ $\mathrm{mg} / \mathrm{dL}, \mathrm{p}<0.001)$. Women with increased HbA1c showed impaired beta-cell function and differences in disposition index independent of body mass index status. We observed a high specificity for the HbA1c cut-off of $5.7 \%$ for GDM manifestation $(0.96,95 \% \mathrm{Cl} 0.91$ to 0.98$)$ or need of glucose-lowering medication $(0.95,95 \% \mathrm{Cl} 0.90$ to 0.98$)$ although overall predictive accuracy was moderate to fair. Further, elevated HbA1c was associated with higher risk for delivering large-for-gestational-age infants, also after adjustment for GDM status (OR 4.4, 95\% $\mathrm{Cl} 1.2$ to 15.0 , $\mathrm{p}=0.018$ ).

Conclusions $\mathrm{HbA} 1 \mathrm{c}$ measured before recommended routine screening period reflects early pathophysiological derangements in beta-cell function and glucose disposal that are characteristic of GDM development and may be useful in early risk stratification.

\section{INTRODUCTION}

Gestational diabetes confers mother and offspring to perinatal and postnatal consequences that are primarily related to degree of maternal hyperglycemia. ${ }^{1}$ Actually, routine diagnostic testing by glucose challenge or

\section{Significance of this study}

What is already known about this subject?

- Several studies reported that women with elevated HbA1c during early pregnancy have a higher risk for gestational diabetes mellitus (GDM) manifestation and/or adverse pregnancy outcomes.

What are the new findings?

- Increased HbA1C $\geq 5.7$ measured during early pregnancy reflects impairments in beta-cell function and glucose disposal that are characteristic of GDM. Pregnant women with elevated HbA1c showed higher glucose levels during oral glucose tolerance test as well as alterations in dynamics.

- Although predictive accuracy of HbA1c was moderate to fair, we observed a high specificity for the HbA1c cut-off of $5.7 \%$ for GDM manifestation or need of glucose-lowering medication.

- Risk for large for gestational age was higher in women with elevated $\mathrm{HbA1C}$ at early pregnancy even after adjustment for GDM status.

How might these results change the focus of research or clinical practice?

- These associations on pathophysiological level argue for the utility of $\mathrm{HbA1C}$ as early predictor for pregnancies at glucometabolic risk that may profit from earlier interventional strategies.

tolerance tests is broadly applied during 24th-28th gestational weeks (GW). However, maternal dysglycemia develops earlier to diagnosis and by crossing the placenta in greater quantities, glucose as a substrate induces fetal overgrowth. ${ }^{1}$ Considering the delay of first clinical contact after laboratory testing as well as time for instruction of self-glucose measurements and implementation of dietary measures considerable time passes where the fetus is exposed to excess intrauterine hyperglycemia. In more severe cases of gestational diabetes mellitus (GDM) this could have detrimental consequences because time for intensive interventions gets limited. 
Various organizations recommend an early screening for glucometabolic disorders during pregnancy but there is no consistent GDM strategy. This condition is already emphasized as it was recently outlined that controversies will remain as long as profound scientific evidence is lacking. ${ }^{23}$ A universal implementation of a strategy would require a simple but effective tool for risk stratification that identifies relevant glucose intolerance with imminent threat for fetal and pregnancy outcome as early as possible-but without elevating associated costs and this is quite challenging. The actual pandemic situation due to the COVID-19 outbreak demonstrates impressively the relevance of fast, reliable and simple parameters that enable appropriate adaptations of diagnostic strategies when access to healthcare services is limited. In this context hemoglobin Alc (HbA1c) gains interest as for its practicability and convenience in clinical practice. Further HbA1c gives an estimate of average glucose over the prior 3 months, why guidelines recommend to set an HbAlc of $6.5 \%$ during first trimester as a threshold for unrecognized pre-existing diabetes. ${ }^{45}$ However, risk for perinatal complications increases in proportion to elevation in maternal HbAlc. ${ }^{6}$ Thus, an HbAlc range below $6.5 \%$ but corresponding to pre-diabetes in nonpregnant state might also have some merit in identifying women with enhanced risk for perinatal complications related to maternal glucose deterioration already during early pregnancy. Against expectation only a few studies focused on HbA1c for evaluation of baseline glycemic situation before regular screening period in second/ third trimester. Most recently, data from a case-control study showed a linear association of HbAlc level and GDM development such that women with $5.7 \%$ HbA1c had an almost three times elevated GDM risk. ${ }^{7}$ Moreover, longitudinal measurements throughout pregnancy remained different between women with GDM and controls. ${ }^{7}$ But before arguing about clinical reliability it is indicated to further characterize the contribution of HbAlc to prediction of GDM by a more detailed evaluation of pathophysiological associations. In this matter, it could be of interest how well HbA1c reflects glucose deterioration and correlates to severity of insulin resistance or beta-cell dysfunction during early gestation.

Thus, we sought to examine the relation of HbAlc to concomitant status of insulin sensitivity and beta-cell function at early pregnancy and to evaluate its accuracy for prediction of GDM manifestation. Further, we evaluated if early maternal HbAlc is independently associated with neonatal birth weight and risk for delivery of largefor-gestational-age (LGA) infants.

\section{RESEARCH DESIGN AND METHODS}

\section{Study population}

This prospective longitudinal study was performed at the Division of Endocrinology and Metabolism, Department of Internal Medicine III, Medical University of Vienna between 2010 and 2014 as previously reported in. ${ }^{8}$
Participants were recruited among all pregnant women at $\leq 21$ st GW, who were referred to our diabetes and pregnancy outpatient clinics in the framework of a tertiary care center. After screening for exclusion criteria (ie, presence of chronic or serious acute infections, hematological diseases or diseases of the hematopoietic system, severely impaired liver or kidney function or infectious diseases) remaining eligible women were asked for consent and were enrolled for further study examinations (visit 1). A total of 223 women underwent further clinical evaluations until delivery at 24th-28th GWs (visit 2), 30th-34th GWs (visit 3) and >36th GW (visit 4). A flow chart describing our study population is given in online supplemental figure $\mathrm{S} 1$.

\section{Clinical examinations and follow-ups}

At initial assignment all participants were characterized by a broad risk evaluation comprising body mass index (BMI) (preconceptional and actual) and medical history. Subsequently, a 2-hour oral glucose tolerance test (OGTT) was performed at visit 1 (median: 16 weeks, IQR: 14-18) after a 10-12 hours overnight fast with glucose, insulin and C-peptide determination after venous blood collection at fasting and after 30, 60, 90 and 120 min following a $75 \mathrm{~g}$ glucose load. Whereas those with OGTT results diagnostic for GDM were immediately assigned for therapeutic regimens, participants with negative OGTT result were clinically examined and repeated OGTT examination at recommended period of 24th-28th weeks (visit 2) to ascertain diagnosis. ${ }^{5}$ Thresholds for diagnosis of GDM were defined by a fasting plasma glucose level of $\geq 92 \mathrm{mg} / \mathrm{dL}$ (but $<126 \mathrm{mg} / \mathrm{dL}$ ), a 1-hour glucose level of $\geq 180 \mathrm{mg} / \mathrm{dL}$ or a 2-hour glucose level of $\geq 153 \mathrm{mg} / \mathrm{dL}$ after glucose load and were applied at first examination in early pregnancy as well as at visit 2 .

At first antenatal visit four women were classified as having pre-existing diabetes by elevated fasting plasma glucose $\geq 126 \mathrm{mg} / \mathrm{dL}$ and/or HbAlc $\geq 6.5 \% \quad(47.54$ $\mathrm{mmol} / \mathrm{mol}$ ) in accordance with the International Association of Diabetes and Pregnancy Study Groups (IADPSG) guidelines $^{5}$ and hence were not eligible for further participation.

Moreover, six women were treated by insulin therapy during later follow-up due to incident macrosomia and elevated fasting glucose and thus were considered as having GDM. Altogether, GDM diagnosis was established primarily by OGTT results according to the IADPSG criteria $^{5}$ or clinical indication of insulin therapy. Analysis of differences in baseline OGTT-derived parameters was previously reported. ${ }^{8}$

\section{Laboratory measurements}

All parameters were measured according to the international standard laboratory methods at our certified Department of Medical and Chemical Laboratory Diagnostics (http://www.kimcl.at/). HbAlc was measured at each visit by the technique of high-performance liquid chromatography using Variant II, Bio-Rad, 
International Federation of Clinical Chemistry (IFCC)standardized and Diabetes Control and Complications Trial (DCCT)-aligned coefficient of variation $(\mathrm{CV})=1.8 \%$ $(\mathrm{HbA1c}=5.6 \%)$. Glucose, insulin and C-peptide were determined from venous blood samples obtained during the OGTT examinations as well as at each further visit, where a venous blood sample was obtained at fasting condition. Plasma glucose concentrations were measured by the hexokinase method with a $\mathrm{CV}$ of $1.3 \%$. Insulin (CV: 4\%-7\%) and C-peptide (CV: 3\%-4\%) were measured by chemiluminescence immune assays.

\section{Calculations}

Total body insulin sensitivity from dynamic OGTT measures of glucose and insulin was assessed by the composite index (ISI-comp, dimensionless), ${ }^{9}$ in addition to the quantitative insulin sensitivity check index (dimensionless), ${ }^{10}$ representing an approximate of hepatic insulin resistance. Insulin secretion was assessed by using modified insulinogenic indices to describe early (Secearly, $\Delta$ insulin/ $\Delta$ glucose 0-30 $\mathrm{min}, \mu \mathrm{U} / \mathrm{mg}$ ), late (Seclate, area under the curve (AUC)-insulin/AUC-glucose 60-120 $\mathrm{min}, \mu \mathrm{U} / \mathrm{mg}$ ) and total insulin response to glucose challenge (Sec-total, AUC-insulin/AUC-glucose 0-120 min, $\mu \mathrm{U} / \mathrm{mg}) .{ }^{11}{ }^{12}$ The oral disposition index (ISSI-2, dimensionless) was calculated as the product of ISI-comp and total insulin secretion to reflect the ability of beta cells to adapt to impaired insulin action. The respective AUCs of glucose, insulin and C-peptide during the OGTT were calculated by using the trapezoidal rule.

\section{Neonatal care and anthropometric measures}

Neonatal birth weight was determined by a calibrated scale. Birth length was measured to the nearest $0.1 \mathrm{~cm}$ by using an infant board with a stadiometer. Age and sex-adjusted percentiles were estimated by applying international anthropometric standards, that is, the INTERGROWTH-21st standards. ${ }^{13}$

\section{Statistical analysis}

Categorical variables were summarized by counts and percentages and compared by Pearson's $\chi^{2}$ test. Continuous variables were summarized by mean $\pm \mathrm{SD}$ as well as median and IQR, respectively. Comparisons of continuous parameters between three groups were performed by Student's t-test and the Wilcoxon rank-sum test (and the Brunner-Munzel test as a supporting approach) was used in case of skewed distributed parameters. An adjustment for covariates such as BMI was performed by analysis of covariance and the proportional odds cumulative logit model, respectively. Binary logistic regression was used to evaluate the association between continuous variables and dichotomous outcomes (eg, GDM manifestation or GDM with need of pharmacotherapy). Thereby, the predictive accuracy of these parameters was assessed by the area under the receiver operating characteristic curves (ROC-AUC). Moreover, statistical performance measures including sensitivity, specificity and predictive values as well as their 95\% CIs are provided as appropriate. Statistical analysis was performed with R (V.3.5.3) and contributed packages. ${ }^{14}$ The two-sided significance level was set to 0.05 . However, $p$ values were interpreted in an explorative manner and there was no further adjustment for multiplicity as not otherwise indicated.

\section{RESULTS}

Descriptive characteristics of the study sample are provided in table 1. Elevated HbAlc was associated with higher pregestational and early pregnancy BMI levels as well as altered glucose dynamics during the OGTT performed at first or early second trimester. Thereby, the subgroup with elevated HbA1c $\geq 5.7$ showed higher fasting, mean as well as maximum glucose concentrations compared with those with HbAlc in normal range $(186.5 \pm 42.6$ vs $147.8 \pm 30.1 \mathrm{mg} / \mathrm{dL}, \mathrm{p}<0.001)$ during this test as visualized in figure 1 . Moreover, the subgroup with elevated HbAlc tended to delay in reaching the maximum concentrations of glucose $(p<0.001)$. Whereas no differences were observed for insulin action either assessed from fasting or dynamic measures, patients with elevated HbA1c showed a notable decrease in early and total insulin secretion, resulting in altered beta-cell function (figure 2A-D). The observed differences in insulin secretion and the ISSI-2 remained constant after controlling for early pregnancy BMI and pregestational BMI, respectively. Furthermore, HbA1c values were associated with the risk for GDM or requirement of insulin during pregnancy. Logistic regression revealed that the predictive accuracy of HbA1c (in terms of ROC-AUC) was moderate to fair and comparable to pregestational BMI $(67.0 \%)$ as presented in figure 3 . The combination of $\mathrm{HbAlc}$ and $\mathrm{BMI}$ increased the predictive performance (ROC-AUC) to $72.4 \%$. However, we observed a high specificity for the HbAlc cut-off of $5.7 \%$ (39 $\mathrm{mmol} / \mathrm{mol}$ ) for GDM manifestation $(0.96,95 \%$ CI 0.91 to 0.98$)$ or need of glucose-lowering medication $(0.95,95 \%$ CI 0.90 to 0.98). Details of performance measures are provided in table 2. In addition, patients with early elevated $\mathrm{HbAlc}$ showed a higher risk for delivering LGA infants (OR 4.2, 95\% CI 1.2 to $13.0, \mathrm{p}=0.016)$ even after adjustment for GDM status (OR 4.4, 95\% CI 1.2 to $15.0, \mathrm{p}=0.018$ ).

\section{CONCLUSIONS}

In our study we observed that increased HbA1c $\geq 5.7$ measured during early pregnancy reflects impairments in beta-cell function and glucose disposal that are characteristic of GDM. Further, HbAlc at early pregnancy may be useful as an indicator of disturbed beta-cell function even independent of BMI. As far as we know, this is the first study providing data of simultaneously performed $75 \mathrm{~g}$ OGTT including insulin and C-peptide measurements in addition to HbAlc during early pregnancy. In our population, increased maternal HbAlc was associated with higher glucose levels during OGTT as well as alterations in dynamics. Moreover, analysis of OGTT-derived indices 
Table 1 Characteristics of the study sample and glucometabolic parameters

\begin{tabular}{|c|c|c|c|c|c|}
\hline & $\mathbf{n}$ & HbA1c $<5.7$ & $\mathbf{n}$ & $\mathrm{HbA1c} \geq 5.7$ & $P$ value \\
\hline Age (years) & 197 & $31.9 \pm 5.2$ & 23 & $33.4 \pm 5.1$ & 0.191 \\
\hline Week of gestation & 197 & $15.9 \pm 2.9$ & 23 & $15.2 \pm 3.2$ & 0.242 \\
\hline Early pregnancy BMI $\left(\mathrm{kg} / \mathrm{m}^{2}\right)$ & 197 & $28.0 \pm 5.7$ & 23 & $32.2 \pm 5.6$ & $<0.001$ \\
\hline Pre-pregnancy BMI (kg/m²) & 196 & $26.5 \pm 5.8$ & 23 & $30.5 \pm 5.4$ & 0.002 \\
\hline GDM & 197 & $67(34.0 \%)$ & 23 & $17(73.9)$ & $<0.001$ \\
\hline IGDM & 197 & $44(22.3 \%)$ & 23 & $15(65.2 \%)$ & $<0.001$ \\
\hline Fasting glucose (mg/dL) & 196 & $79.7 \pm 7.2$ & 23 & $90.4 \pm 13.2$ & $<0.001$ \\
\hline 60 min post-OGTT glucose (mg/dL) & 196 & $138.9 \pm 34.6$ & 23 & $182.6 \pm 44.3$ & $<0.001$ \\
\hline $120 \mathrm{~min}$ post-OGTT glucose $(\mathrm{mg} / \mathrm{dL})$ & 196 & $106.0 \pm 26.8$ & 23 & $131.3 \pm 32.3$ & $<0.001$ \\
\hline Mean glucose (mg/dL) & 180 & $116.2 \pm 21.4$ & 22 & $145.6 \pm 31.4$ & $<0.001$ \\
\hline Maximum glucose (mg/dL) & 180 & $147.8 \pm 30.1$ & 22 & $186.5 \pm 42.6$ & $<0.001$ \\
\hline Fasting insulin $(\mu \mathrm{U} / \mathrm{mL})$ & 196 & $4.38(1.90-8.51)$ & 23 & $3.71(2.31-9.09)$ & 0.709 \\
\hline Mean insulin $(\mu \mathrm{U} / \mathrm{mL})$ & 178 & $39.9(28.8-62.7)$ & 22 & $40.7(26.1-62.8)$ & 0.901 \\
\hline Fasting C-peptide (ng/mL) & 195 & $1.40(1.10-2.00)$ & 23 & $1.80(1.45-2.70)$ & 0.010 \\
\hline Mean C-peptide (ng/mL) & 178 & $6.63(5.33-8.20)$ & 22 & $7.26(5.91-9.27)$ & 0.158 \\
\hline Early insulin secretion $(\mu \mathrm{U} / \mathrm{mg})$ & 187 & $76.9(48.7-122.5)$ & 22 & $39.5(24.2-73.4)$ & 0.001 \\
\hline Late insulin secretion $(\mu \mathrm{U} / \mathrm{mg})$ & 177 & $43.5(31.0-65.1)$ & 22 & $38.8(25.8-52.9)$ & 0.108 \\
\hline Total insulin secretion $(\mu \mathrm{U} / \mathrm{mg})$ & 177 & $38.4(26.1-57.0)$ & 22 & $29.6(21.9-42.2)$ & 1960.039 \\
\hline QUICKI (dimensionless) & 195 & $0.40 \pm 0.05$ & 22 & $0.39 \pm 0.05$ & 0.362 \\
\hline ISI-comp (dimensionless) & 170 & $9.27 \pm 5.63$ & 22 & $7.86 \pm 5.22$ & 0.265 \\
\hline ISSI-2 (dimensionless) & 170 & $319 \pm 128$ & 22 & $213 \pm 129$ & $<0.001$ \\
\hline
\end{tabular}

Data are mean $\pm \mathrm{SD}$, median (IQR) or counts and percentages for patients with normal and elevated $\mathrm{HbA1c}$ at early pregnancy.

BMI, body mass index; GDM, gestational diabetes mellitus; HbA1c, hemoglobin A1c; IGDM, insulin-treated gestational diabetes mellitus; ISI-comp,

composite index; ISSI-2, oral disposition index; OGTT, oral glucose tolerance test; QUICKI, quantitative insulin sensitivity check index.

showed impaired beta-cell function and differences in disposition index in women with increased HbAlc which were independent of early pregnancy BMI or pregestational BMI status.

Characteristic of GDM is the insufficient compensation of increasing insulin requirements during pregnancy primarily due to defective beta-cell function. ${ }^{1}{ }^{15}$ Concomitant to changes in the insulin signaling cascade, the growing placenta produces hormones with insulin-desensitizing effects that increase insulin resistance-here maternal adiposity gains relevance as an antecedent risk factor during early pregnancy that defines level of basal insulin sensitivity. ${ }^{116}$ To sum up, maintenance of euglycemia during gestation depends mainly on the plasticity of maternal beta-cell function to sufficiently compensate insulin resistance, which aggravates depending on additional metabolic risk factors

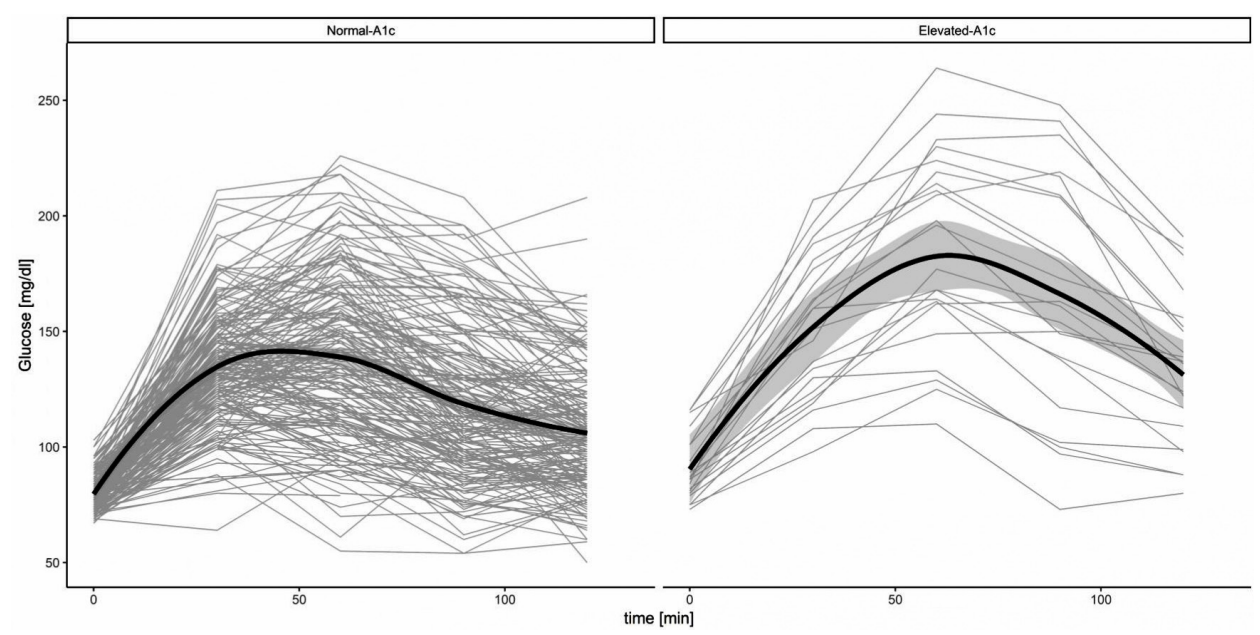

Figure 1 Spaghetti plots of plasma glucose dynamics during a 2-hour oral glucose tolerance test (OGTT) in pregnant women with normal $(<5.7 \%)$ and elevated $(\geq 5.7) \mathrm{HbA1c}$ levels at early gestation. The solid line represents the weighted mean value and the gray area represents the $95 \% \mathrm{Cl}$. $\mathrm{HbA1c}$, hemoglobin A1c. 
A

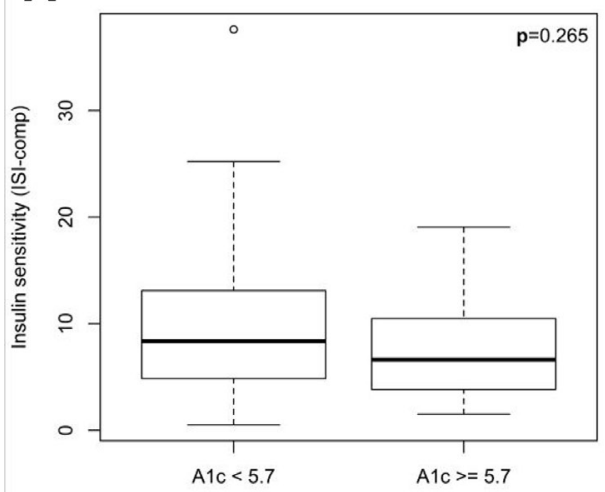

C

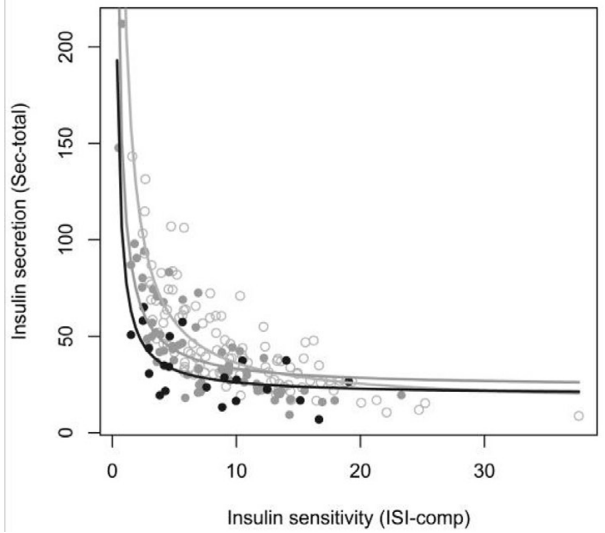

B

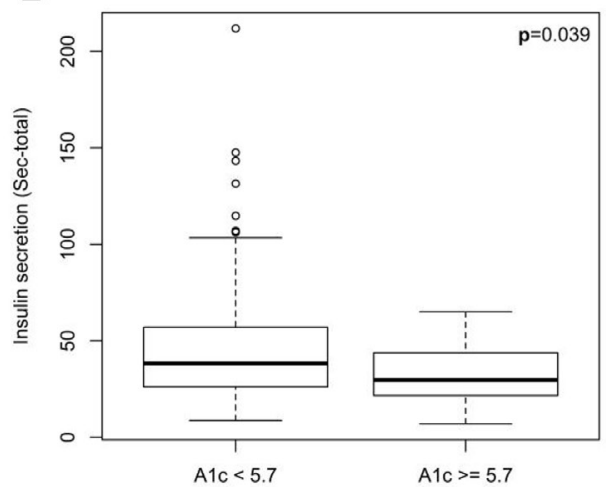

D

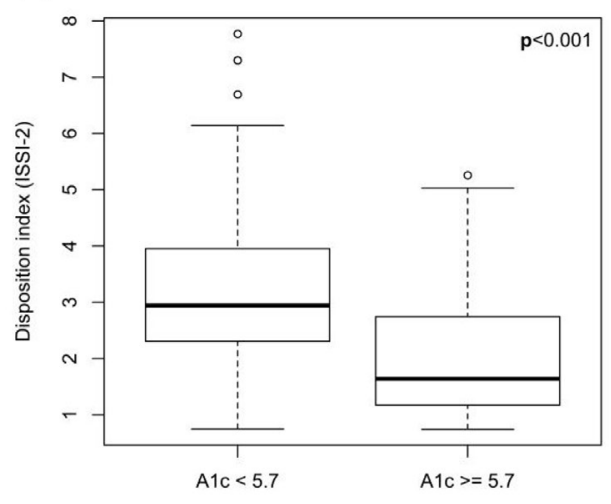

Figure 2 Box-whisker plots representing comparisons of insulin sensitivity (A) and insulin secretion (B) from the oral glucose tolerance test (OGTT), the association between insulin sensitivity and insulin secretion and the estimated hyperbolic regression line for normal glucose-tolerant controls (light gray) as well as women with gestational diabetes mellitus (GDM) and normal $\mathrm{HbA1c}$ (dark gray) and women with elevated $\mathrm{HbA1c}$ (black) (C) as well as the disposition index, representing beta-cell function (D). HbA1c, hemoglobin A1c.

during pregnancy—otherwise it is a matter of time that GDM becomes evident. ${ }^{15}$ However, measures indicating beta-cell function or the disposition index require too extensive and precise procedures including multiple blood samples and thus are inconvenient for first trimester screening. HbA1c during early pregnancy may give an estimate of the maternal glucose metabolism at baseline before significant hormonal pregnancy-related changes develop-thus it offers an
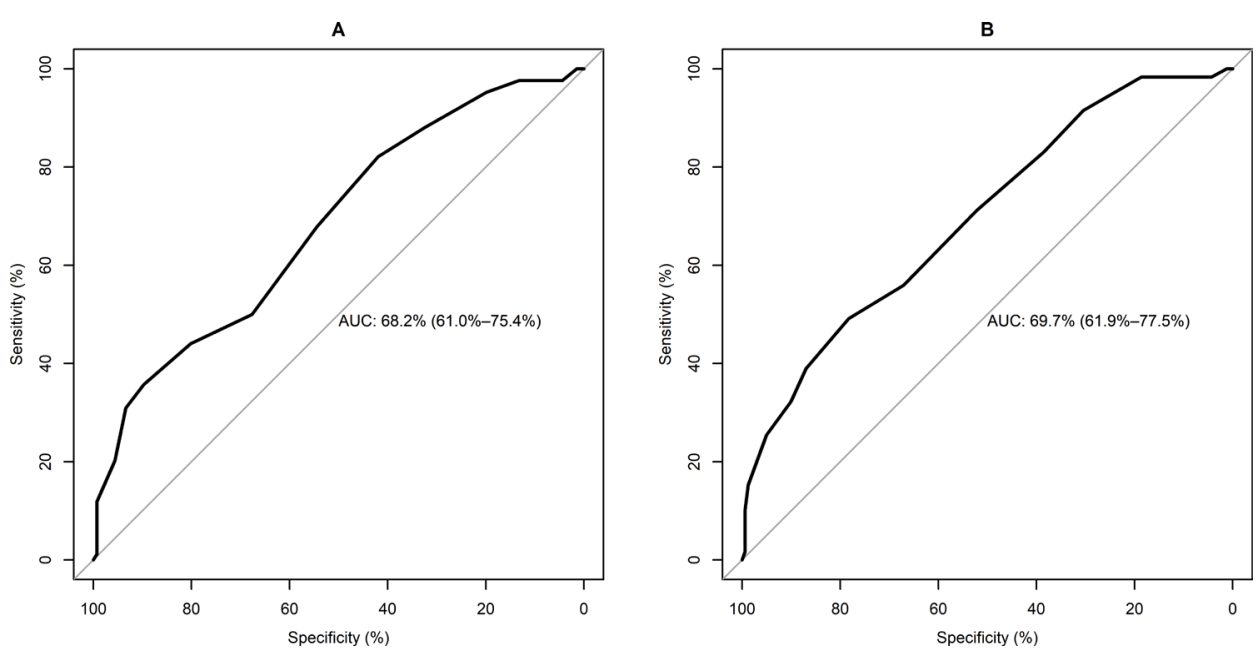

Figure 3 Receiver operating characteristic (ROC) curves for presumption of gestational diabetes mellitus (GDM) prediction (A) and of initiation of pharmacotherapy in GDM (B) by HbA1c levels at early gestation. AUC, area under the curve; HbA1c, hemoglobin A1c. 


\begin{tabular}{lll}
\hline \multicolumn{2}{l}{ Table 2} & \multicolumn{2}{l}{ Performance measures of $\mathrm{HbA} 1 \mathrm{c} \geq 5.7 \%$} \\
\hline & GDM & IGDM \\
\hline $\begin{array}{l}\text { Apparent } \\
\text { prevalence }\end{array}$ & $0.10(0.07$ to 0.15$)$ & $0.10(0.07$ to 0.15$)$ \\
$\begin{array}{l}\text { True prevalence } \\
\text { Sensitivity }\end{array}$ & $0.38(0.32$ to 0.45$)$ & $0.27(0.21$ to 0.33$)$ \\
$\begin{array}{l}\text { Specificity } \\
\text { Positive predictive }\end{array}$ & $0.20(0.12$ to 0.30$)$ & $0.25(0.15$ to 0.38$)$ \\
$\begin{array}{l}\text { value } \\
\text { Negative predictive } \\
\text { value }\end{array}$ & $0.66(0.91$ to 0.98$)$ & $0.95(0.90$ to 0.98$)$ \\
\hline
\end{tabular}

Data are statistical performance measures and 95\% Cls. GDM, gestational diabetes mellitus; HbA1c, hemoglobin A1c; IGDM, insulin-treated gestational diabetes mellitus.

opportunity to identify those women who could benefit of tighter glycemic control at very early stage of gestation. In our study, we could demonstrate that HbAlc $>5.7 \%$ is associated with lower levels of disposition index, which reflects compensatory effectiveness of beta-cell function in answer to insulin resistance. We further observed that $\mathrm{HbAlc}$ is related to later insulin requirement, which is another corroborating aspect for the predictive value of early measured HbAlc.

Since HbAlc is already broadly applied during first routine antenatal visit for detection of pregestational diabetes, implementation of HbAlc in GDM risk stratification becomes an attractive option. Several studies already reported that women with elevated $\mathrm{HbAlc}$ during early pregnancy have a higher risk for GDM and/or adverse pregnancy outcomes. In a retrospective analysis Osmundson $e t$ al showed that risk for GDM was increased by 50\% (adjusted RR, 1.48; 95\% CI 1.15 to 1.89 ) in women with first trimester HbA1c of $5.7 \%-$ $6.4 \%$ compared with women with an HbAlc in normal range. ${ }^{17}$ Other studies concluded similarly that HbAlc levels referred for pre-diabetes outside of pregnancy are associated with GDM manifestation and hereby supported the prognostic applicability of HbA1c in GDM risk prediction. ${ }^{6718}$ Of interest, in a very recent retrospective cohort study pregravid $\mathrm{HbA1c}$ measured at median 1.4 years before pregnancy was shown to be a robust predictor of GDM. For each $0.1 \%$ elevation of pregravid HbAlc the odds of GDM in a subsequent pregnancy was increased by $22 \%$ - however, the authors could not define a threshold for pregravid HbAlc that is implementable to reduce the burden of OGTT screening during pregnancy. ${ }^{19}$

Similar to our findings, several previous studies concluded an overall limited predictive ability of $\mathrm{HbAlc}$ at prediabetic level. ${ }^{6717-19}$ After reviewing indicated test characteristics of former studies we could detect limitations in comparability of these to our results mainly due to the differences in study design. Our observations of a relatively high specificity but low sensitivity at an HbA1c cut-off of 5.7\% for GDM development are very similar to the findings of the retrospective study by Osmundson $e t$ al, who equally used the IADPSG criteria for GDM diagnosis and applied the same threshold for their analysis. ${ }^{17}$ As far as applicable, we could further extract similar test characteristics (ie, specificity and sensitivity) for a cut-point of $5.7 \%$ from studies, which differ regarding to diagnosis criteria (ie, the two-step screening by Carpenter and Coustan criteria with preceding challenge test) and the primary choice of a lower threshold. ${ }^{72021}$ Further, it has to be considered that HbAlc changes throughout pregnancy ${ }^{7}$ which may explain why only moderate correlations are detectable between early $\mathrm{HbAlc}$ and glucose examinations in third trimester. However, we are now confronted with the challenge that during an outbreak of pandemic disease measures for containment of virulent infection are required, which limit indications for time-consuming OGTTs-here simple algorithms comprising rapidly obtainable parameters would facilitate preparation of temporary guidelines that adequately balance their benefits versus burden in disease management during special conditions. Thus, the actual COVID-19 pandemic shows that it is worth to direct attention towards large-scale studies comparing different approaches for use in exceptional situations.

Moreover, we observed that elevated maternal $\mathrm{HbAlc}$ at early pregnancy is associated with a higher risk for delivering LGA infants even after adjustment for GDM status. Hughes et al as well found a higher rate of LGA newborns based on population-adjusted percentiles ${ }^{6}$ whereas others reported no significant difference in birth weight. ${ }^{1721}$ However, available data are not powered to identify neonatal differences. The use of HbAlc during early pregnancy represents average glucose level over the prior 3 months and thus might be a better predictor of very early influences on fetal development that are not covered by mid-pregnancy to late pregnancy glucose-based testing. Of further interest is if any early intervention based on maternal HbAlc brings a benefit for pregnancy and/or neonatal outcome-but this aspect is so far not sufficiently addressed in randomized trials. In a study with small sample size it was shown that early treatment for women with $\mathrm{HbAlc}$ in prediabetic range did not significantly reduce overall rate of GDM diagnosis in 24th-28th GWs but in a subgroup analysis of non-obese women, GDM risk was decreased by $50 \%{ }^{22}$ Recently, Roeder et al aimed to examine the effects of early treatment on neonatal hyperinsulinemia and fat mass in women with $\mathrm{HbA1c} \geq 5.7 \%$ and/or fasting glucose $\leq 92 \mathrm{mg} / \mathrm{dL}$. The study stopped early because of low enrollment but presented data showed so far no significant benefit. ${ }^{23}$ In another study, investigators randomized obese women to compare early screening prior to 20th week to routine screening, whereby women with $\mathrm{HbAlc}$ between $6.2 \%$ and $6.5 \%$ at initial contact were provided with early screening regardless of randomization arm. Altogether, they found no reduction of composite perinatal outcome between in those who received early screening. ${ }^{24}$

Current recommendations mostly fail to consider women with pre-existing deteriorations in glucose hemostasis who enter pregnancy with glucose elevations below the threshold used for overt diabetes. Further, lack of agreement on uniform screening standards during early pregnancy additionally hardens comparability of studies aiming to characterize high-risk pregnancies. In summary, our data show that early HbAlc $\geq 5.7 \%$ but below overt diabetes reflects 
impairments in beta-cell function and glucose disposal that are indicative for underlying defects in compensation mechanisms and risk for early GDM. These associations on pathophysiological level argue for the utility of HbAlc as early predictor for pregnancies at glucometabolic risk that warrant further research.

Contributors LB and AKW conceived the study. Data assessment and patient recruitment were performed by LB, KL and CSG. Statistical analysis, calculations and data interpretation were performed by CSG and LB. The manuscript was written by LB. CSG, GP and AKW reviewed and edited the manuscript.

Funding This study was supported by the Medical Scientific Fund of the Mayor of Vienna (PrNr: 09063) to AKW.

Competing interests None declared.

Patient consent for publication Not required.

Ethics approval This study was approved by the Ethics Committee of the Medical University of Vienna on 19 February 2009 (reference number: 771/2008) and performed in accordance with the Declaration of Helsinki. All participants gave written informed consent to participate in this study.

Provenance and peer review Not commissioned; externally peer reviewed.

Data availability statement Data are available upon reasonable request from the authors.

Supplemental material This content has been supplied by the author(s). It has not been vetted by BMJ Publishing Group Limited (BMJ) and may not have been peer-reviewed. Any opinions or recommendations discussed are solely those of the author(s) and are not endorsed by BMJ. BMJ disclaims all liability and responsibility arising from any reliance placed on the content. Where the content includes any translated material, BMJ does not warrant the accuracy and reliability of the translations (including but not limited to local regulations, clinical guidelines, terminology, drug names and drug dosages), and is not responsible for any error and/or omissions arising from translation and adaptation or otherwise.

Open access This is an open access article distributed in accordance with the Creative Commons Attribution Non Commercial (CC BY-NC 4.0) license, which permits others to distribute, remix, adapt, build upon this work non-commercially, and license their derivative works on different terms, provided the original work is properly cited, appropriate credit is given, any changes made indicated, and the use is non-commercial. See: http://creativecommons.org/licenses/by-nc/4.0/.

ORCID iD

Alexandra Kautzky-Willer http://orcid.org/0000-0002-3520-4105

\section{REFERENCES}

1 Mclntyre HD, Catalano P, Zhang C, et al. Gestational diabetes mellitus. Nat Rev Dis Primers 2019;5:47.

2 Wexler DJ, Powe CE, Barbour LA, et al. Research gaps in gestational diabetes mellitus: Executive summary of a national Institute of diabetes and digestive and kidney diseases workshop. Obstet Gynecol 2018;132:496-505.

3 Huhn EA, Rossi SW, Hoesli I, et al. Controversies in screening and diagnostic criteria for gestational diabetes in early and late pregnancy. Front Endocrinol 2018;9:696.

4 Hughes RCE, Rowan J, Florkowski CM. Is there a role for HbA1c in pregnancy? Curr Diab Rep 2016;16:5.

5 Metzger BE, Gabbe SG, Persson B, Kitzmiler JL, et al. International association of diabetes and pregnancy study groups recommendations on the diagnosis and classification of hyperglycemia in pregnancy: response to Weinert. Diabetes Care 2010;33:e98-82.

6 Hughes RCE, Moore MP, Gullam JE, et al. An early pregnancy $\mathrm{HbA} 1 \mathrm{c} \geq 5.9 \%(41 \mathrm{mmol} / \mathrm{mol})$ is optimal for detecting diabetes and identifies women at increased risk of adverse pregnancy outcomes. Diabetes Care 2014;37:2953-9.

7 Hinkle SN, Tsai MY, Rawal S, et al. $\mathrm{HbA}_{1 \mathrm{c}}$ Measured in the First Trimester of Pregnancy and the Association with Gestational Diabetes. Sci Rep 2018;8:12249.

8 Bozkurt L, Göbl CS, Pfligl L, et al. Pathophysiological characteristics and effects of obesity in women with early and late manifestation of gestational diabetes diagnosed by the International association of diabetes and pregnancy study groups criteria. J Clin Endocrinol Metab 2015;100:1113-20.

9 Matsuda M, DeFronzo RA. Insulin sensitivity indices obtained from oral glucose tolerance testing: comparison with the euglycemic insulin clamp. Diabetes Care 1999;22:1462-70.

10 Katz A, Nambi SS, Mather K, et al. Quantitative insulin sensitivity check index: a simple, accurate method for assessing insulin sensitivity in humans. J Clin Endocrinol Metab 2000;85:2402-10.

11 Tura A, Kautzky-Willer A, Pacini G. Insulinogenic indices from insulin and C-peptide: comparison of beta-cell function from OGTT and IVGTT. Diabetes Res Clin Pract 2006;72:298-301.

12 Lorenzo C, Williams K, Haffner SM. Insulin secretion based on the late oral glucose tolerance test period and incident diabetes: the San Antonio heart study. Diabet Med 2012;29:e151-8.

13 Villar J, Cheikh Ismail L, Victora CG, et al. International standards for newborn weight, length, and head circumference by gestational age and sex: the newborn cross-sectional study of the Intergrowth-21st project. Lancet 2014;384:857-68.

14 R Core Team. R: a language and environment for statistical computing. $R$ foundation for statistical computing. Vienna, Austria, 2019. http://www.R-project.org/

15 Powe CE, Huston Presley LP, Locascio JJ, et al. Augmented insulin secretory response in early pregnancy. Diabetologia 2019;62:1445-52.

16 Barbour LA, McCurdy CE, Hernandez TL, et al. Cellular mechanisms for insulin resistance in normal pregnancy and gestational diabetes. Diabetes Care 2007;30 Suppl 2:S112-9.

17 Osmundson SS, Zhao BS, Kunz L, et al. First trimester hemoglobin A1c prediction of gestational diabetes. Am J Perinatol 2016;33:977-82.

18 Amylidi S, Mosimann B, Stettler C, et al. First-Trimester glycosylated hemoglobin in women at high risk for gestational diabetes. Acta Obstet Gynecol Scand 2016;95:93-7.

19 Retnakaran R, Shah BR. Pregravid $\mathrm{HbA}_{1}$ and Glucose Measurement to Rule Out Future Gestational Diabetes Mellitus and Reduce the Need for Oral Glucose Tolerance Testing in Pregnancy. Diabetes Care 2020;43:e93-5.

20 Boe B, Barbour LA, Allshouse AA, et al. Universal early pregnancy glycosylated hemoglobin A1c as an adjunct to Carpenter-Coustan screening: an observational cohort study. Am J Obstet Gynecol MFM 2019;1:24-32.

21 Fong A, Serra AE, Gabby L, et al. Use of hemoglobin A1c as an early predictor of gestational diabetes mellitus. Am J Obstet Gynecol 2014;211:641.e1-641.e7.

22 Osmundson SS, Norton ME, El-Sayed YY, et al. Early screening and treatment of women with prediabetes: a randomized controlled trial. Am J Perinatol 2016;33:172-9.

23 Roeder HA, Moore TR, Wolfson MT, et al. Treating hyperglycemia in early pregnancy: a randomized controlled trial. Am J Obstet Gynecol MFM 2019;1:33-41.

24 Harper LM, Jauk V, Longo S, et al. Early gestational diabetes screening in obese women: a randomized controlled trial. $A m \mathrm{~J}$ Obstet Gynecol 2020;222:495.e1-495.e8. 